TITLE:

\title{
Microscopic characteristics of partially saturated dense sand and their link to macroscopic responses under triaxial compression conditions
}

\author{
$\operatorname{AUTHOR}(S)$ :
}

Kido, Ryunosuke; Higo, Yosuke

\section{CITATION:}

Kido, Ryunosuke ... [et al]. Microscopic characteristics of partially saturated dense sand and their link to macroscopic responses under triaxial compression conditions. Acta Geotechnica 2020, 15: 3055-3073

\section{ISSUE DATE:}

2020-11

URL:

http://hdl.handle.net/2433/259161

\section{RIGHT:}

This is a post-peer-review, pre-copyedit version of an article published in 'Acta Geotechnica'. The final authenticated version is available online at: https://doi.org/10.1007/s11440-020-01049-w.; The full-text file will be made open to the public on 04 August 2021 in accordance with publisher's 'Terms and Conditions for Self-Archiving'.; この論文は出版社版 でありません。引用の際には出版社版をご確認ご利用ください。; This is not the published version. Please cite only the published version. 


\section{Microscopic characteristics of partially saturated dense sand and their link to macroscopic responses}

2

3

4

5

$6{ }^{1}$ Department of Civil and Earth Resources Engineering, Kyoto University, Kyotodaigaku-Katsura, Nishikyo-ku,

7 Kyoto 615-8540, Japan. (kido.ryunosuke.2m@kyoto-u.ac.jp)

8 ORCID iD https://orcid.org/0000-0002-5204-0130

92 Department of Urban Management, Kyoto University, Kyotodaigaku-Katsura, Nishikyo-ku, Kyoto 615-8540,

10 Japan. (higo.yohsuke.5z@ kyoto-u.ac.jp)

11 ORCID iD https://orcid.org/0000-0003-0694-1322

13 Corresponding author: Yosuke Higo, Department of Urban Management, Kyoto University, Kyotodaigaku-

14 Katsura, Nishikyo-ku, Kyoto 615-8540, Japan, +81-75-383-3305, higo.yohsuke.5z@kyoto-u.ac.jp.

Keywords: partially saturated sand, triaxial compression test, X-ray micro tomography, liquid bridge, principal 


\section{Abstract}

This paper presents a set of triaxial compression tests on partially saturated dense sands to clarify the microscopic

characteristics and their link to the macroscopic responses. Constant suction tests (CS tests) and constant water content tests (CW tests) are conducted under low confining pressure to observe microscopic and macroscopic

behaviors of the sands associated with dilative shear bands. X-ray micro tomography and image analysis

techniques are applied to investigate the continuity as a defined index to evaluate the morphology of the pore water,

the number of liquid bridges and the principal curvature of the air-water interface. The number of liquid bridges

decreases for both the CS and CW tests, particularly during the strain softening process, while it decreases greater

in the CW test than in the CS test. The curvature of the air-water interface remains at almost the same value under the CS test, while it tends to decrease under the CW test. The tendency of decreasing curvature corresponds to that

of decreasing suction in the $\mathrm{CW}$ test. The peak deviator stress is higher in the CS test than in the CW test when the pore water is initially discontinuous, whereas it is identical between the two tests when the pore water is initially

continuous. The residual stress is lower in the $\mathrm{CW}$ test than in the CS test, independent of the initial water retention poorly-graded sand and well-graded sand. 


\section{Introduction}

Water retention states in partially saturated soils are varied with degrees of saturation and are classified into

pendular, funicular and capillary states [36]. In the pendular state, liquid bridges exist between soil particles due to the surface tension of water and the hydrophilic property of the soil, where suction (difference between pore air pressure and pore water pressure) enhances the shear stiffness and the shear strength of partially saturated soils (e.g., $[8-12,30,37,40])$. In order to investigate mechanical characteristics of partially saturated soils, triaxial compression tests have been conducted under a drained condition for water (e.g., $[4,13,31])$ and un undrained condition for water (e.g., $[2,31,35,43])$. These studies have revealed that higher suction levels provide the higher shear strength, while suction tends to decrease with shearing under the undrained condition for water, particularly in the case of higher initial levels of suction. It is also known that partially saturated soil exhibits more brittle modes of failure associated with clearer shear bands than fully saturated soil (e.g., $[5,16,17])$. The effect of suction on the mechanical behavior of partially saturated soil depends on the water retention states (e.g., $[21,26,41])$, and hence the effect changes due to the variation in water retention states as shearing progresses. These macroscopic responses of partially saturated soil under triaxial compression must be interpreted by three-phase microstructural changes; however, the microscopic interpretation has not been sufficiently done. This is because observation of the three-phase microstructural changes associated with the development of shear bands in partially saturated soil is difficult using conventional techniques.

An X-ray tomography technique has been widely used to observe the density change in geomaterials since the pioneering study by [7]. In recent years, an X-ray micro tomography technique has enabled discussions on the 
water retention behavior and the three-phase structural changes of partially saturated granular materials from a microscopic viewpoint. It was revealed that, at low saturation degrees, a large number of water units having very small volume (liquid bridges) exist and the number of liquid bridges decreases with increasing water saturation [42]. Microscopic characteristics such as the air-water interfacial contact angle [29], pore water distribution changes during drying process [20], and capillary collapse due to increasing water content [3] were clearly observed. Specific air-water interfacial areas in partially saturated glass bead samples and their influence on the material strength were quantitatively discussed [39]. Further studies are still needed, however, in order to clarify the link of grain- and pore-scale characteristics to the macroscopic responses for various kinds of soils under partial saturation conditions.

The objective of the present study is to clarify the microscopic characteristics of partially saturated sands under triaxial compression and their link to the macroscopic responses. Triaxial compression tests on partially saturated sands are conducted under drained conditions for air and water, and a drained condition for air and an undrained condition for water. Dilative behaviors of dense sand specimens under low confining pressure are investigated, considering partially saturated soils near the ground surface such as well-compacted embankments. Poorly-graded silica sand, which is advantageous for high spatial resolution image acquisition using an X-ray micro tomography, is used to investigate the three-phase microstructural changes associated with the development of shear bands. Preliminarily, research group of the authors revealed that void ratio increased and the degree of saturation decreased as shear bands develop $[19,22]$, and that the tendency for decreasing the number of grain contacts and water menisci was closely related to the macroscopic strain softening behavior [23]. In the present study, variations 
73 in the morphology of the pore water, the number of liquid bridges and the principal curvature of the air-water

interface with the development of shear bands are investigated by image analysis techniques using the tomographic

volumes. For the poorly-graded sand, it is difficult to measure the suction change during triaxial compression test

because the change is quite small due to its low water retention capability. Hence, well-graded sand, which shows

much higher water retention capability than the poorly-graded sand, is also tested and suction is measured during

triaxial compression. Through comparison between the measured macroscopic suction changes and the variation

in the microscopic principal curvature of the air-water interface, progressive changes of suction and morphological transitions of pore water during triaxial compression are demonstrated. The influence of the quantified microscopic

characteristics on the deviator stress-axial strain relationship for partially saturated sand with different initial degrees of saturation, under triaxial compression with the different drained conditions for water, is discussed.

\section{Experimental Setup}

\subsection{Material and specimen preparation}

\subsubsection{Poorly-graded sand}

Poorly-graded sand, whose particles have a diameter of several hundred $\mu \mathrm{m}$, are generally used for the visualization of the microstructure using X-ray micro tomography due to the limitation of the spatial resolution. Kido and Higo (2017) [22] confirmed that sufficiently high accuracy of the image analyses was achieved when the diameter of sand particles corresponded to 27 voxels. For the experimental setup in the present study, the available voxel size is $12 \mu \mathrm{m}$. With this resolution, sand particles with a $D_{50}$ larger than $324 \mu \mathrm{m}$ are required for 
92 the subsequent image analyses. Thus, silica sand No. 5, whose $D_{50}$ is $456 \mu \mathrm{m}$, was used in the present study.

Figures 1a and 2 present a SEM image of the silica sand and its grain size distribution curve, respectively. The physical properties of silica sand include a soil density of $2.64 \mathrm{~g} / \mathrm{cm}^{3}$, a maximum void ratio of 1.013 , a minimum void ratio of 0.694 , a uniformity coefficient of 1.3 and a fines content of $0.1 \%$. The target relative density $\left(D_{\mathrm{r}}\right)$ of the triaxial specimens was $90 \%$ since earth structures, such as road embankments and river levees, are well compacted. Figure 3 shows the water retention curve for the silica sand with a $D_{\mathrm{r}}$ of $90 \%$. A water retention test was performed using the negative water column technique [38]. The suction level of less than $10 \mathrm{kPa}$ gives the residual degree of saturation of about $20 \%$, which means that the water retention capability of silica sand is rather low.

An acrylic pedestal was equipped with a water-saturated ceramic disc. The air entry value (AEV) of the ceramic disc is 0.5 bar $(50 \mathrm{kPa})$ which is much higher than the water retention capability of silica sand. Air-dried sand was poured directly from a certain height into the water that was filled in the mold with a diameter of $35 \mathrm{~mm}$ beforehand. Then, the sand was densely packed by tapping the mold. Once the packed sand had reached a height of $70 \mathrm{~mm}$, a top cap was placed on the specimen and negative pressure of $10 \mathrm{kPa}$ was applied inside the specimen through the cap to stabilize the specimen by a difference in pressure to remove the mold. A confining pressure of $10 \mathrm{kPa}$ was applied in the triaxial cell and then the negative pressure of $10 \mathrm{kPa}$, applied inside the specimen through the cap, was removed. After that, the confining pressure was increased to $50 \mathrm{kPa}$. The top of the specimen was released through a water tank to atmospheric pressure, i.e., a pore air pressure of $0 \mathrm{kPa}$, with almost $100 \%$ humidity, as shown in Fig. 4a. As shown in this figure, suction was applied to the specimen by the water head difference 
between the top of the specimen and the water table in the burette connected to the bottom of the specimen in order to desaturate the specimen.

\subsubsection{Well-graded sand}

The water retention capability of silica sand is quite low, as shown in Fig. 3; and hence, it is difficult to measure the variation in suction during triaxial compression. In order to investigate the contributions of suction to the macroscopic responses, triaxial compression tests using well-graded sand with a higher water retention capability were performed. The well-graded sand used in the present study is Yodogawa sand which is typical on-site soil and has been used to improve river levees in Japan. A SEM image of the Yodogawa sand is shown in Fig. 1b.

Figure 2 shows a grain size distribution curve reflecting $73 \%$ sand, 15\% silt and $12 \%$ clay (e.g., [25]). The physical properties of Yodogawa sand include a soil density of $2.66 \mathrm{~g} / \mathrm{cm}^{3}$, an optimum water content of $13.7 \%$ and a maximum dry density of $1.86 \mathrm{~g} / \mathrm{cm}^{3}$. The water retention curve for Yodogawa sand with a degree of compaction $\left(D_{\mathrm{c}}\right)$ of $90 \%$ is shown in Fig. 3. The water retention test was performed using both the negative water column technique with $5 \mathrm{kPa}$ of suction and the pressure plate method [32] with over $5 \mathrm{kPa}$ of suction. It is clearly seen that the water retention capability of Yodogawa sand is much higher than that of silica sand.

Yodogawa sand was mixed with a water content less than the optimum water content of $13.0 \%$. The mixed sand was statically compacted in a mold, $35 \mathrm{~mm}$ in diameter and $70 \mathrm{~mm}$ in height. The target $D_{\mathrm{c}}$ was $90 \%$ which is the standard for earth structures determined by the Japan Institute of Construction Engineering (2002). The static compaction was done in five equal layers, with each layer having a thickness of $14 \mathrm{~mm}$. The interfaces between 
the different layers were carefully scarified.

Each compacted specimen was placed on an acrylic pedestal which was equipped with a water-saturated ceramic disc with an air entry value (AEV) of $50 \mathrm{kPa}$, and a polyflon filter was set on top of the specimen to measure and control the pore air pressure and the pore water pressure independently. The specimen was set in the triaxial cell and a cell pressure of $20 \mathrm{kPa}$ was firstly applied by air pressure. The cell pressure was increased up to $60 \mathrm{kPa}$, while the pore air pressure inside the specimen was increased up to $40 \mathrm{kPa}$ under an undrained water condition.

Before the triaxial compression tests, the drained water and consolidation processes were performed. Suction was applied by the axis translation technique (for details see, e.g., [38]); namely, the pore water pressure, lower than the pore air pressure of $40 \mathrm{kPa}$, was increased up to a certain value corresponding to a target level of suction. For example, a suction of $30 \mathrm{kPa}$ is given by $40 \mathrm{kPa}$ in pore air pressure and $10 \mathrm{kPa}$ in pore water pressure. The cell pressure was increased up to $90 \mathrm{kPa}$, resulting in a confining pressure of $50 \mathrm{kPa}$. The process to drain the water was begun by opening the valve for the water path connected to the bottom of the specimen. The open marks of

Fig. 3 are the water retention states of the tested specimens. These plots are located outside of the area bounded by the drying and wetting curves because the wetting curve is not really a main wetting curve, but one of scanning curves.

\subsection{X-ray micro tomography}

The X-ray micro tomography facility used in the present study is KYOTO-GEO $\mu$ XCT (TOSCANER-

32250 $\mu$ hdk, TOSHIBA IT and Control Systems Corporation) [24], as shown in Fig. 4b. The cone-beam type of 
scanning collects the attenuation characteristic of X-rays for several horizontal cross sections in the vertical direction at the same time, and the three-dimensional CT volume is obtained by the image reconstruction. The Xray tomography with two kinds of spatial resolution was performed at axial strain levels of $0 \%, 2 \%, 4 \%, 6 \%, 9 \%$, 12\%, 15\%, $18 \%$ and 21\% for the silica sand, as shown in Fig. 5. One of them is global tomography, used to observe the entire specimen over a larger scan region. The other is local tomography, used to observe the local region of interest focusing on the shear band with higher spatial resolution, enough to identify individual soil particles and water retention states. Once the sand fails due to the shear band, the macroscopic responses of the sand seem to be predominant in the microstructural changes inside the shear band. Hence, the local region, including the shear band, was observed. The scan position of the local tomography, as shown in Fig. 5, is moved by triaxial compression. Thus, the scan position was adjusted at each axial strain, by which nearly the same region of interest was tracked until the end of the triaxial compression test. Voxel size of the global tomography was $77.7^{2} \times 85.0 \mu \mathrm{m}^{3}$, while that of the local tomography was $12.3^{2} \times 14.0 \mu \mathrm{m}^{3}$. Axial loading was suspended during both kinds of X-ray tomography for around two hours, after which it was resumed at the same strain rate. For Yodogawa sand, only the global tomography was performed at axial strains of $0 \%, 2 \%, 4 \%, 6 \%, 9 \%, 12 \%, 16 \%, 20 \%, 24 \%$ and $27 \%$.

\subsection{Test methods and conditions}

Triaxial compression tests were conducted for both materials under a low confining pressure of $50 \mathrm{kPa}$ to investigate the strength property of partially saturated sand which exhibits dilation during shearing, assuming, for example, the near surface of embankments. The strain rate was $0.10 \% / \mathrm{min}$. 
In the present study, the triaxial compression tests on the partially saturated sand were conducted under two

kinds of conditions. One is drained conditions for both air and water, in which the pore air pressure and the pore

water pressure are constant during shearing; namely, the suction is constant. The other is a drained condition for air and an undrained condition for water, in which the pore water pressure is varied while maintaining the constant pore air pressure during shearing; namely, the suction is varied. The former condition assumes that partially saturated soil deforms without any excess pore water pressure due to slow shearing or the high permeability of the water content test with an initial suction of $30 \mathrm{kPa}$.

\section{Image analysis methodologies}

\subsection{Trinarization}


One voxel mostly includes a gray value corresponding to one phase, while another voxel shares more than two

phases. In this case, the gray value of the voxel is determined using the average density of their phases, which is

called the partial volume effect. For partially saturated sand, there are three types of voxels due to the partial

volume effect: the voxel sharing the soil particle phase and the pore water phase, the voxel sharing the pore water

phase and the pore air phase and the voxel sharing the soil particle phase and the pore air phase, respectively. The

gray value for the voxel sharing the soil particle phase and the pore air phase is similar to that for the pore water

phase and, as such, the voxel is often misidentified as the pore water phase. Thus, the partial volume effect for

partially saturated sand often causes an overestimation of the pore water volume [18].

For the segmentation of the soil particle phase, the pore water phase and the pore air phase, the CT images have

been trinarized using the region growing method (e.g., [17]). The trinarization technique used in the present study

takes into account the voxels due to the partial volume effect separately from those of the pure soil, water and air

phases when determining the tolerance of the region growing. This technique reasonably identifies the voxels due

to the partial volume effect as the pore air phase; and therefore, the overestimation of the pore water volume is

reduced as much as possible. The region growing technique is applied to the soil particle phase and the pore air

phase, after which the pore water phase is given as the remaining voxels. The detail algorithm and the validity of

the trinarization technique are described in [24].

\subsection{Morphology analysis}

The scope of this analysis is to reveal the morphological changes of the pore air and the pore water in the 
partially saturated sand under triaxial compression. In the present study, the pore air phase and the pore water phase extracted from the trinarized volumes are divided into some assemblies with individual continuity, referred to as clusters, using the 3D image analysis software Avizo9.4.0 (FEI). Figure 6 shows an example of the trinarized image and the labeled image obtained by this image analysis. There exist pore water voxels due to the partial

volume effect as well as the absorbed water surrounding the soil particles in the trinarized volume. The pore water

voxels are removed using erosion and dilation (e.g., [15]) with two voxels in this order. The separated pore water

212 is then labeled by assigning a unique number to all adjacent voxels that constitute a cluster, as shown in Fig. 6b.

213 The cluster volumes and the number of clusters are quantified. The detail algorithm is described in [24].

214 Here, an index "continuity" is defined as a ratio of a maximum cluster volume to a total cluster volume and the 215 value range is from $0 \%$ to $100 \%$. Based on this index, water retention states were identified as the following three

states: 1) the continuity is almost $100 \%$ and $0 \%$ for water and air, respectively, 2) the continuity is almost $100 \%$

for both water and air and 3) the continuity is almost $0 \%$ and $100 \%$ for water and air, respectively [24]. It was also

confirmed that the three states corresponded to insular-air saturation, funicular saturation and pendular saturation regimes [1] in this order. Therefore, the "continuity" is an indicator to identify the water retention states depending on saturation degrees. It should be noted, however, that the continuity does not strictly describe whether the pore water is continuous in reality but does just describe morphology of pore water, because the absorbed water (thin water film) around particles, via which the pore water is continuous in soils, is ignored. The voxels related to the absorbed water were removed during the erosion-dilation image processing. 


\subsection{Curvature analysis}

226 [28]):

$$
u_{a}-u_{w}=\frac{T}{r_{1}}-\frac{T}{r_{2}}
$$

229 where $u_{a}$ is the pore air pressure, $u_{w}$ is the pore water pressure, $u_{a}-u_{w}$ is the suction, $r_{1}$ and $r_{2}$ are the 230 radii of the principal curvature of the air-water interface and $T$ is the surface tension of water which is $0.074 \mathrm{~N} / \mathrm{m}$ 231 at $20^{\circ} \mathrm{C}$. Suction is positive for partially saturated soil; hence, $r_{1}$ is always smaller than $r_{2} \cdot r_{1}$ and $r_{2}$ are 232 presented as follows [6]:

$$
\begin{gathered}
r_{1}=R\left(\frac{1}{\cos \theta}-1\right) \quad r_{2}=R \tan \theta-r_{1} \\
0^{\circ} \leq \theta \leq 53^{\circ} \quad r_{1}<r_{2}, u_{a}-u_{w}>0 \\
53^{\circ} \leq \theta \leq 90^{\circ} \quad r_{1} \geq r_{2}, u_{a}-u_{w} \leq 0
\end{gathered}
$$

233 where $R$ is the radius of an ideal sphere, and $\theta$ is the filling angle of the pore water between ideal spheres. It is 234 probable that particle shapes affect air-water interface curvatures, and hence the equation (1) may not be accurate 235 for non-spherical particle. In the present study, since the particle shape of the silica sand, whose aspect ratio is

roughly 1.5 from Fig. 1a, is relatively spherical among general soils, equation (1) is here assumed to be applicable.

Figure 7 shows the relationship between suction and principal curvature radii $r_{1}$ and $r_{2}$ based on equations (1) and (2) when $R$ is $230 \mu \mathrm{m}$, which is almost equivalent to half of the $D_{50}$ of each silica sand particle. This figure indicates that $r_{1}$ is two orders of magnitude smaller than $r_{2}$ with suction of $2.0 \mathrm{kPa}$ which works in the triaxial 
specimens of the silica sand. Additionally, the suction estimated by equation (1) monotonically increases as $r_{1}$ decreases. This result confirms that the variation in suction can be sufficiently discussed by measuring $r_{1}$. Hence, in the present study, principal curvature $1 / r_{1}$ is calculated by an image analysis to evaluate suction.

In the present study, the maximum value of principal curvature is calculated as the curvature of the air-water interface, $1 / r_{1}$, using the 3D image processing software Avizo9.4.0 (FEI). Generally, the rate of change of the normal direction in given tangential directions is measured by the second fundamental form (e.g., [27]), i.e., curvature tensor, which can be expressed by a symmetric two-by-two matrix. The eigenvalues of the matrix are the principal curvatures. In the image processing, curved surfaces are subdivided into triangular meshes, and then

the second fundamental form on each triangular mesh is approximated to the computed normal deviations of the triangle mesh using a least-squares method. As a result, the maximum eigenvalue, namely, the maximum principal

curvature, is calculated. Details of the algorithm, implemented in this software, are given in [33].

applied for the binary image of the pore water in order to remove the voxels for the pore water phase with respect

to the partial volume effect and adsorbed water. The processed pore water phase is replaced with the original one,

and then the air-water interface is extracted as shown in Fig. 8a. The interface is composed of numerous triangular

calculation is the number zero, the triangles sharing the sides of the target triangle are assumed to be number one.

Similarly, numbers are assigned to the triangles up to twenty, as shown in Fig. $\mathbf{8 b}$. The triangles adjacent to the 
approximated with the least squares method to minimize the errors (deviation) in the principal curvatures for all the considered triangles. This indicates that the principal curvature at a certain triangular mesh on the interface is approximated to be equivalent to those of the adjacent triangles. Subsequently, the median of the principal curvatures for all triangles is determined as the curvature of the air-water interface $1 / r_{1}$ because a histogram of the curvatures obtained by the curvature analysis follows the log-normal distribution.

The validation of the curvature analysis was investigated. Firstly, the influence of the number of neighboring target triangles (see Fig. 8b) on the accuracy of the calculation of the principal curvature was investigated using a realistic virtual sphere with a diameter of 41 voxels whose voxel size is $12 \mu \mathrm{m}$ on one side. It was found that the number of neighboring target triangles of twenty provided a more similar principal curvature to the theoretical one.

evaluating the principal curvature of the material was investigated. The curvature analysis was applied to realistic virtual spheres with five diameters, namely, 17 voxels, 19 voxels, 21 voxels, 31 voxels and 41 voxels, whose voxel

size is $12 \mu \mathrm{m}$ on one side. Figure 9 shows a comparison of the calculated and the theoretical solutions, which

272 indicates that both values have a linear relationship with the correlation coefficient of 0.971 . Therefore, the

curvature analysis supposed in the present study is an appropriate method for discussing the relative levels of the

274 principal curvature of the air-water interface, i.e., suction.

\section{Results}

\subsection{Macroscopic responses}


1278

2

3

4

5

6

7

8

\subsubsection{Deviator stress-axial strain relationships}

Figure 10 shows the deviator stress-axial strain relationships and the volumetric strain-axial strain relationships.

280 The volume of the specimen at each axial strain was measured by counting the number of voxels corresponding 281 to the specimens out of the global tomography volumes (see [16]). Several vertical short lines in the stress-strain

strain are kept constant during X-ray tomography. The previous study [16] confirmed that the stress relaxation did

not have significant effect on the overall response of sand specimens under triaxial compression. It is found that the stress-strain curves for all cases exhibit strain hardening followed by strain softening, accompanied by volume expansion with an increasing axial strain.

As displayed in Fig. 10a, cases CS1 and CW1 show almost the same peak deviator stress at an axial strain of $6 \%$. The stress-strain curves and the changes in volumetric strain until the residual stress are also similar to each other. The significant difference between the two cases is that, for case CW1, the deviator stress at an axial strain of $27 \%$, hereinafter referred to as residual stress, is lower than that for case CS1. Similarly, almost the same peak deviator stress is obtained at an axial strain of $9 \%$ between cases CS-s10 and CW-s10, whereas the residual stress

for case CW-s10 is lower than that for case CS-s10. These results confirm that the stress-strain curves for cases

CS1 and CW1 are qualitatively identical to those for cases CS-s10 and CW-s10, respectively. As displayed in Fig.

10b, the difference in deviator stress is more significant; namely, the peak deviator stress and the residual stress for cases CW2 and CW-s30 are lower than those for cases CS2 and CS-s30, respectively. These results confirm that the stress-strain curves for cases CS2 and CW2 are qualitatively identical to those for cases CS-s30 and CW- 
s30, respectively.

Figure 11 shows the amount of drained water during loading for cases CS-s10 and CS-s30. It can be seen that 299 the water is drained with increasing axial strain, indicating that the water retention capability of the specimens 300 becomes lower due to dilation.

\subsubsection{Suction for Yodogawa sand}

Figure 12 shows the suction-axial strain relationship, for which the suction is given by the difference between the pore air pressure of $40 \mathrm{kPa}$ and the pore water pressure measured in the tests. The constant levels of suction of $10 \mathrm{kPa}$ and $30 \mathrm{kPa}$ are maintained during the triaxial compression tests for cases CS-s10 and CS-s30, respectively. On the other hand, the suction decreases at the early stage of shearing for cases CW-s10 and CW-s30. For case $\mathrm{CW}$-s10, the suction recovers to almost the initial level of suction of $10 \mathrm{kPa}$, after which it tends to slightly decrease as shearing progresses. In contrast, the suction for case CW-s30 greatly decreases with an increasing axial strain, although a slight increase in suction is observed at an axial strain of $3 \%$. The same trend, namely, decreasing suction under an undrained condition for water during shearing, was observed in previous studies (e.g., [35]).

\subsubsection{Macroscopic deformation observed by global tomography}

Figure 13 shows representative vertical slices of the CT images obtained by global tomography and distributions of shear strain calculated by digital image correlation, namely, DIC (e.g., [14, 17, 34]). The displacement fields were obtained by DIC with a zero-normalized cross-correlation coefficient between the reference and deformed 
CT images. Shear strain levels are provided by the B matrix for the eight-node isoparametric finite elements and the second invariant of incremental deviatoric strain tensor is defined as the incremental shear strain (see [17] for details). In the CT images, the materials with high density, such as metal, are described by the whiter color, while

those with low density, such as air and the dilated regions, are described by the black color. It is clearly seen from

the vertical slices at an axial strain of $0 \%$ for cases CS1, CS2, CW1 and CW2 that the upper part of the specimens is blacker than the bottom part. This indicates that the distribution of the degrees of saturation in the specimens is heterogeneous at the initial condition. This is because a higher level of suction is imposed on the upper part of the specimens by the negative water column technique; thus, a greater amount of water is drained. The lower density

region increases at the middle of the specimens with an increasing axial strain due to dilation. As shown by the

This region apparently corresponds to where the larger shear strains locally occur, indicating that the lower density

region developing locally in the specimen is a shear band. Clearer shear bands can be observed in the specimens

for cases CS1 and CS2 than for cases CW1 and CW2 probably because a greater degree of volume change is allowed during shearing in the drained conditions for both air and water than in the drained condition only for air.

It is found from Fig. 13 that, for the Yodogawa sand, the middle part of the specimens dilates significantly and then the blacker portions increase as shearing progresses. The shear bands are invisible from the CT images for cases CS-s10 and CS-s30; however, the DIC analysis provides the clear shear strain localization in the upper right

direction. In contrast, for cases CW-s10 and CW-s30, no clearer shear bands are observed than those for cases CS-

s10 and CS-s30. It is found from the above results that the failure mode of the specimens for the silica sand is 
1

2

3

4336

5

6

qualitatively identical to that for the Yodogawa sand during shearing.

\subsection{Microscopic characteristics}

\subsubsection{Local void ratio and degree of saturation in trinarized volumes}

of dilative shear bands.

inherent metal inclusions in the silica sand. The metal inclusions were regarded as the soil particle phase in the trinarized images. In the CT images, the lower density region in the upper right direction can be observed beyond an axial strain of 9\%; namely, this region is spatially consistent with the shear band observed by global tomography.

The trinarized slices demonstrate that the amount of pore water becomes smaller in the shear band than in the other portions, which suggests that the reduction in the water retention capability is mainly attributed to the development for cases CS1 and CW1 are denser. The local void ratios for all cases tend to be increased up to an axial strain of

$12 \%$. The changes in the local void ratio become small beyond an axial strain of $15 \%$, indicating that the sand is

getting closer to the critical state. Reductions in the void ratio are observed at some of axial strain levels, although 
354 the shearing progresses. This is probably attributed to a limitation of the local CT volume, which contains both dilated loose portions inside the shear bands and less-dilated or contracted dense portions outside the shear bands.

Depending on the ratio of dense and loose portions, the calculated void ratio of the local volume possibly decreases.

Nevertheless, the trend of increasing void ratio and approaching the critical state can be clearly seen in Fig. 15.

\subsubsection{Water retention states in trinarized volumes evaluated by morphology analysis}

Variations in the water retention states in the trinarized volumes under triaxial compression were investigated based on the continuity for pore water and pore air. Figure 17 shows the variations in continuity for the pore water 
and the pore air. The continuity for the pore air is kept at almost $100 \%$ for all cases. The continuity for the pore water decreases with an increasing axial strain for cases CS1 and CW1, whereas it remains at almost $0 \%$ for cases

CS2 and CW2. Figures 18a to 18d show the labeled images of the pore water cluster at axial strain levels of $0 \%$, $4 \%$ and $15 \%$ for cases CS1, CS2, CW1 and CW2, respectively. It is clearly seen that, for cases CS1 and CW1 with high initial degrees of saturation, one continuous pore water cluster with large volume transits into discontinuous pore water clusters with increasing axial strain. For cases CS2 and CW2 with low initial degrees of saturation, the pore water clusters remain discontinuous state during loading. Figure 18e demonstrates examples of the discontinuous pore water clusters existing as liquid bridges between soil particles.

Figures 19a to 19d show the cumulative volume of pore water clusters-cluster volume relationships for cases $\mathrm{CS} 1, \mathrm{CS} 2, \mathrm{CW} 1$ and CW2, respectively. It can be seen that one cluster with volume larger than $1.7 \times 10^{6}$ voxels $\left(3.6 \mathrm{~mm}^{3}\right)$, showing $100 \%$ cumulative volume, exists at several levels of axial strain for cases CS1 and CW1. In the present study, the cluster with volume larger than $1.7 \times 10^{6}$ voxels is regarded as the continuous pore water cluster (a labeled image at an axial strain of $0 \%$ in, e.g., Fig. 18a), while the clusters with volume smaller than $1.7 \times 10^{6}$ voxels are regarded as the discontinuous pore water clusters (a labeled image at an axial strain of $0 \%$ in e.g., Fig. 18b). In the present study, it is assumed that the discontinuous pore water clusters are identified as liquid bridges. Although some of the discontinuous pore water clusters may comprise a few liquid bridges even if the volume of such clusters is smaller than $1.7 \times 10^{6}$ voxels, the clusters play a role of bonding between particles and are obviously different from the continuous pore water which exists as a much larger volume cluster.

Figure 20 illustrates the number density of the discontinuous pore water clusters-axial strain relationship. The 
number density is calculated by dividing the number of the discontinuous pore water clusters by the total volume of the discontinuous pore water clusters. In other words, the number density means the number of liquid bridges per unit pore water volume. It can be seen that the number densities for cases CS1 and CW1 tend to decrease with increasing axial strain up to $12 \%$, and then turn to increase slightly beyond an axial strain of $15 \%$. The increase in the number density indicates that the continuous pore water transits into the discontinuous pore water with small

volume due to dilation, as shown in Figs. 18a and 18c. On the other hand, the number density for case CW2 is

smaller and tends to decrease more greatly than that for case CS2 with increasing axial strain. At the initial state,

there is a relatively big difference in the level of the number density between cases CS2 and CW2, even though

lower degree of saturation, the water retention state and the volume distribution of pore water will vary by just a

little difference in the local degree of saturation. It is therefore quite difficult to investigate a local part of each

tomography.

It is found from Figs. 10 and $\mathbf{2 0}$ that, except for the result at an axial strain of $4 \%$, the number density for case

CW1 is almost the same as that for case CS1 until an axial strain of $6 \%$ where the peak deviator stresses for the two cases are similar to each other. The smaller number density at the axial strain of $4 \%$ for case $\mathrm{CW} 1$ possibly results from a variation in the local void ratio. As seen in Fig. 15, the void ratio for case CW1 greatly increases

which reduces the number of liquid bridges. Investigating variation in grain contacts would be important to clarify 
this point. On the other hand, the smaller number density is observed in case CW1 than in case CS1 at axial strains of $18 \%$ and $21 \%$, corresponding to the lower residual stress in case CW2 than in CS2. It is also found that the number density for case CW2 is smaller than that in case CS2 at both an early stage of shearing and the residual state, corresponding to the lower peak deviator stress and the lower residual stress in case CW2 than in case CS2.

\subsubsection{Variation in principal curvature of air-water interface}

417 Figure 21 shows the principal curvature of the air-water interface-axial strain relationship in the trinarized 418 volumes. The principal curvatures of the air-water interface at an axial strain of $0 \%$ for cases CS2, CW2, CW1 419 and CS1 are higher in this order; they correspond to the magnitude correlation of the initial levels of suction for

to an axial strain of $21 \%$, and comparable to the test condition under which the macroscopic suction remains

under an undrained condition for water during shearing decreases as the shearing progresses.

constant during shearing. The principal curvature of the air-water interface for case CS2 tends to be also similar at each axial strain. On the other hand, the principal curvatures of the air-water interface for cases CW1 and CW2 tend to gradually decrease with increasing axial strain and finally become lower than those for cases CS1 and CS2 at an axial strain of $21 \%$, respectively. These results confirm that the principal curvature of the air-water interface

principal curvatures of the air-water interface for cases CS1 and CS2, respectively. In addition, the decrease in the 
levels of suction for cases $\mathrm{CW}$-s10 and $\mathrm{CW}$-s30 corresponds to the decrease in the principal curvatures of the airwater interface for cases CW1 and CW2, respectively. Therefore, the decrease in suction under the undrained condition for water during shearing can be interpreted as the decrease in the principal curvature of the air-water interface.

\section{Discussions}

\subsection{Effects of drained conditions for water on microscopic characteristics of pore water}

437 Increasing the void ratio due to dilation causes a decrease in the degree of saturation as the shearing progresses,

438 and then the water retention state in partially saturated sand with higher initial degrees of saturation tends to transit

439 from a continuous pore water cluster to discontinuous pore water clusters (see Figs. 18a and 18c). These trends

440 are independent of the drained conditions for water during shearing. In water retention test [24], a continuous pore

441 water cluster with large volume transited into discontinuous pore water clusters with smaller volume during the

442 drying process. Decreasing degree of saturation, either by dilation or by drying causes the transition of the pore

443 water morphology from the continuous state to the discontinuous state. On the other hand, under the undrained

444 condition for water during shearing, the number of liquid bridges decreases more greatly than under the drained

445 condition for water during shearing and there exists the smaller number of liquid bridges (see Fig. 20). Additionally,

446 the principal curvature of the air-water interface under the undrained condition for water during shearing tends to

447 decrease, whereas that under the drained condition for water during shearing remains almost constant.

448 The cause of the decrease in the number of liquid bridges under the undrained condition for water during 
shearing is interpreted in terms of the variation in the principal curvature of the air-water interface. Let us consider the liquid bridges between the ideally spherical grain contacts and the radius of the principal curvature of the airwater interface, $r_{1}$, presented by equation (2). As shown in equation (2), the pore water can exist as liquid bridges

and suction works with $\theta$ smaller than $53^{\circ}$. Assuming that $R$ is $228 \mu \mathrm{m}$ for the silica sand grains and the range in the principal curvatures of the air-water interface in the present study is from $0.009 \mu \mathrm{m}^{-1}$ to $0.014 \mu \mathrm{m}^{-1}$ (see Fig.

21), the range in $\theta$ is between $40^{\circ}$ and $48^{\circ}$; and thus, liquid bridges can exist between the grains. The principal curvature of the air-water interface decreases in the undrained condition for water during shearing, which

corresponds to the increase in $r_{1}$ in equation (2). Considering that $R$ is constant, the increase in $r_{1}$ causes the

compression with the undrained condition for water is attributed to the decrease in the principal curvature of the

interface, but mainly to the decrease in grain contacts under the drained condition for water during shearing. Thus,

there is a larger decrease in the number of liquid bridges in the undrained condition for water.

\subsection{Link of microscopic characteristics to macroscopic responses}

Firstly, the link of microscopic characteristics to the peak deviator stress is discussed. Figure 10b indicates that 
the partially saturated silica sand with low initial degrees of saturation displays higher peak deviator stress under the CS test compared to that under the CW test. For both cases, a lot of liquid bridges (the discontinuous pore water with the continuity of almost $0 \%$ as shown in Fig. 17) initially exist as indicated by Figs. 18b, 18d and 18e.

The grains are strongly bonded together due to suction working as inter-particle force through the liquid bridges.

initial suction are almost the same between the CS test and the CW test of the silica sand, the number of liquid

bridges tends to decrease more greatly induced by the decrease in the principal curvature of the air-water interface under the CW test, resulting in the lower peak deviator stress than under the CS test. This idea is supported by the results obtained in the $\mathrm{CW}$ test with high level of initial suction for Yodogawa sand; the level of suction (the principal curvature of the air-water interface) is significantly decreased at an early stage of loading, resulting in the lower peak deviator stress than under the CS test.

On the other hand, Fig. 10a indicates that the levels of peak deviator stress for the silica sand with high initial degrees of saturation under the CS test and the CW test are identical to each other; this trend is consistent with the levels of peak deviator stress for the Yodogawa sand with low initial suction. A continuous pore water exists in the partially saturated silica sand as indicated by labeled images at an axial strain of 0\% in Figs. 18a and 18c. Assuming

continuous water retention state, the effect of suction through liquid bridges on the bonding between grains is less

significant than in the discontinuous water retention state. In cases CS-s10 and CW-s10 for the Yodogawa sand, 
the pore water is more continuous than that in the cases with high level of suction, and there is little difference in the measured suction between the two cases at the peak deviator stress with an axial strain of about $6 \%$ as shown in Fig. 12. Thus, the contribution of suction, mainly due to bulk water, to the shear stiffness and the shear strength,

is similar between the CS test and the CW test, leading to the identical levels of peak deviator stress between them.

Secondly, the link of microscopic characteristics to the residual stress is discussed. As indicated in Fig. 10a, the residual stress for the silica sand and the Yodogawa sand under the CW test is lower than that under the CS test.

Even though the pore water is initially continuous, it becomes discontinuous as shearing progresses; namely, the proportion of liquid bridges increases. The tendency for a decrease in the number of liquid bridges during the postpeak softening process can be observed for both the CS test and the CW test. However, under the CW test the principal curvature of the air-water interface, i.e., the suction, decreases and becomes lower than that under the CS test during the post-peak softening process even if the levels of initial suction are the same. Additionally, the number of liquid bridges decreases by a greater degree than in the CS test. As a result, the contribution of the suction through liquid bridges to the shear stiffness and the shear strength of the partially saturated soil becomes lower under the $\mathrm{CW}$ test than under the CS test during the post-peak softening process. This provides the difference in residual stress between $\mathrm{CW}$ and CS tests. In residual stress state of Yodogawa sand, the deviator stress and the measured suction of the CW test are smaller than those of the CS test (see Figs. 10b and 12), and the difference in deviator stress between the two tests is clearer than that of the silica sand. The same trend of the Yodogawa sand as the silica sand confirms that the deviator stress at the critical state is smaller in the CW test than in the CS test. 


\section{Concluding remarks}

Triaxial compression tests under drained conditions for both air and water (constant suction test, i.e., CS test)

508 and those under a drained condition for air and an undrained condition for water (constant water content test, i.e.,

509 CW test) were conducted on dense specimens with partially-water saturated conditions. Triaxial tests were carried

510 out under low confining pressure to investigate soil behaviors associated with dilative shear bands. Silica sand was

511 used as the poorly-graded sand in order to clarify the microscopic characteristics of pore water using X-ray micro

512 tomography and image analysis techniques. Yodogawa sand, i.e., typical on-site soil, was used as the well-graded

513 sand in order to measure the suction variation and to confirm the findings obtained using the silica sand.

514 Trinarization quantified changes in the void ratio and degree of saturation. Morphology analysis classified the 515 continuous water cluster, i.e., bulk water, and the discontinuous water clusters, i.e., liquid bridges. Curvature 516 analysis of air-water interface provided the suction changes. Using these image analysis results, the link of the 517 microscopic characteristics to the macroscopic responses of the partially saturated silica sand was revealed. 518 Although the differences of the macroscopic stress-strain responses and the microscopic analyzed quantities such 519 as the curvature between CS test and CW test seems small for the silica sand, these findings were successfully 520 supported by the tests using the Yodogawa sand, in which the tendencies are the same as those of the silica sand

and the differences of stress-strain behaviors and measured suction were sufficiently clear.

of saturation were similar. However, the morphology of the pore water and curvatures of the air-water interface 
were clearly different depending on drained conditions during shearing and initial degrees of saturation. The relationships between the microscopic characteristics and the macroscopic responses of the partially saturated soil under different initial water retention states clarified in this study are summarized in Fig. 22.

In cases of high initial degrees of saturation (Fig. 22a), pore water exists as bulk water rather than liquid bridges and the suction mainly contributes to isotropic effective stress. Although suction slightly decreases in CW test,

there are little difference in suction levels between CS test and CW test due to the low suction level. Hence, the

effect of suction on shear stiffness and shear strength are similar between the two tests, resulting in almost the

same peak deviator stress. As shearing progresses, the water retention state becomes discontinuous with dilation,

the air-water interface, i.e., suction, gradually decreases in CW test, leading to a greater decrease in the number of

bridges rather than through bulk water. Since the suction level is higher than that of the high saturation cases,

suction decreases more greatly in CW test, resulting in lower peak deviator stress. The number of liquid bridges

decreases with dilation as shearing progresses. Similar to the high saturation cases, the decrease in the curvature

of the air-water interface induces a greater decrease in the number of liquid bridges in $\mathrm{CW}$ test, which results in

lower deviator stress in CW test than that in CS test at the residual stress state. 
As future work, it will be important to clarify the cause of the decrease in the principal curvature of air-water interface under the $\mathrm{CW}$ test. It will also be important to investigate the microscopic characteristics of partially saturated contractive sand and their link to the macroscopic responses.

software Avizo9.4.0 (FEI) in the present study.

\section{References}

1. Bear J (1979) Hydraulics of Groundwater. McGraw-Hill, New York

2. Bishop AW, Alpan I, Blight, GE, Donald, IB (1960) Factors controlling the shear strength of partly saturated cohesive soil. In: Proceedings of the ASCE Research Conference on Shear Strength of Cohesive Soils: 503532

3. Bruchon JF, Pereira JM, Vandamme M, Lenoir N, Delage P, Bornert M (2013) Full 3D investigation and characterisation of capillary collapse of a loose unsaturated sand using X-ray CT. Granular Matter 15(6): 783800

4. Cui YJ, Delage P (1996) Yielding and plastic behavior of an unsaturated compacted silt. Géotechnique 46(2): $291-311$

5. Cunningham MR, Ridley AM, Dineen K, Burland JB (2003) The mechanical behavior of a reconstituted unsaturated silty clay. Géotechnique 53(2): 183-194

6. Dallavalle JM (1943) Micrometrics. Pitman, Inc., London

7. Desrues J, Chambon R, Mokni M, Mazerolle F. (1996) Void ratio evolution inside shear bands in triaxial sand 
specimens studied by computed tomography. Géotechnique 46(3): 539-546

8. Escario V (1980) Suction controlled penetration and shear tests. In: Proceedings of the 4th International Conference on Expansive Soils. ASCE, Denver, 2: 781-797

9. Escario V, Saez J (1986) The shear strength of partly saturated soils. Géotechnique 36: 453-456

10. Fredlund DG, Morgenstern NR, Widger RA (1978) The shear strength of unsaturated soils. Canadian Geotechnical Journal 15: 313-321

11. Fredlund DG, Rahardjo H (1993) Soil Mechanics for Unsaturated Soils. Wiley, Inc., New York

12. Gan JKM, Fredlund DG, Rahardjo H (1988) Determination of the shear strength parameters of an unsaturated soil using the direct shear test. Canadian Geotechnical Journal 25: 500-510

13. Geiser F, Laloui L, Vulliet L (2006) Elasto-plasticity of unsaturated soils: laboratory test results on a remoulded silt. Soils and Foundations 46(5): 545-556

14. Hall SA, Bornert M, Desrues J, Pannier Y, Lenoir N, Viggiani G, Bésuelle P (2010) Discrete and continuum analysis of localised deformation in sand using X-ray $\mu \mathrm{CT}$ and volumetric digital image correlation. Géotechnique 60(5): 315-322

15. Haralick RM, Sternberg SR, Zhuang X (1987) Image Analysis Using Mathematical Morphology. IEEE Transactions on Pattern Analysis and Machine Intelligence 9(4): 532-550

16. Higo Y, Oka F, Kimoto S, Sanagawa T, Matsushima Y (2011) Study of strain localization and microstructural changes in partially saturated sand during triaxial tests using microfocus X-ray CT. Soils and Foundations 51(1): 95-111

17. Higo Y, Oka F, Sato T, Matsushima Y, Kimoto S (2013) Investigation of localized deformation in partially saturated sand under triaxial compression using microfocus X-ray CT with digital image correlation. Soils and Foundations 53(2): 181-198

18. Higo Y, Oka F, Morishita R, Matsushima Y, Yoshida T (2014) Trinarization of $\mu X$-ray CT images of partially saturated sand at different water retention states using a region growing method. Nuclear Instruments and Methods in Physics Research B (324): 63-69

19. Higo Y, Oka F, Morishita R, Matsushima Y (2015) Quantitative Observation of Strain Localisation in a Partially Saturated Triaxial Specimen Using Microfocus X-ray CT with Image analysis. In: Proceedings of the 10th International Workshop on Bifurcation and Degradation in Geomaterials: 325-330

20. Higo Y, Kido R, Takamura F, Fukushima Y (2018) Pore-scale investigations of partially water-saturated granular soil. Mechanics Research Communications 94: 1-7

21. Karube D, Kawai K (2001) The role of pore water in the mechanical behavior of unsaturated soils. Geotechnical and Geological Engineering 19: 211-241

22. Kido R, Higo Y (2017) Evaluation of distribution of void ratio and degree of saturation in partially saturated triaxial sand specimen using micro x-ray tomography. JGS special publication 5(2): 22-27

23. Kido R, Higo Y (2019) Distribution changes of grain contacts and menisci in shear band during triaxial compression test for unsaturated sand. Japanese Geotechnical Society Special Publication 7(2):627-635

24. Kido R, Higo Y, Takamura F, Morishita R, Khaddour G, Salager S (2020) Morphological transitions for pore water and pore air during drying and wetting processes in partially saturated sand. Acta Geotechnica 15: 
1745-1761

25. Kimoto S, Oka F, Fukutani J, Yabuki T, Nakashima K (2011) Monotonic and cyclic behavior of unsaturated sandy soil under drained and fully undrained conditions. Soils and Foundations 51(4): 663-681

26. Kohgo Y, Nakano M, Miyazaki T (1993) Theoretical aspects of constitutive modelling for unsaturated soils. Soils and Foundations 33(4): 49-63

27. Kreyszig E (2013) Differential Geometory. Dover Publications, Inc., New York

28. Lu N, Likos WJ (2004) Unsaturated Soil Mechanics. John Wiley Sons, Inc., Hoboken, N.J

29. Manahiloh KN, Meehan CL (2017) Determining the Soil Water Characteristic Curve and Interfacial Contact Angle from Microstructural Analysis of X-Ray CT Images. Journal of Geotechnical and Geoenvironmental Engineering 143(8): 1-11

30. Rahardjo H, Lim TT, Chang MF, Fredlund DG (1995) Shear-strength characteristics of a residual soil. Canadian Geotechnical Journal 32: 60-77

31. Rahardjo H, Heng OB, Choon LE (2004) Shear strength of a compacted residual soil from consolidated drained and constant water content triaxial tests. Canadian Geotechnical Journal 41: 421-436

32. Richards LA (1948) Porous plate apparatus for measuring moisture retention and transmission by soil. Soil Science 66(2): 105-110

33. Rieger B, Timmermans FJ, van Vliet LJ, Verbeek PW (2004) On curvature estimation of ISO surfaces in 3D gray-value images and the computation of shape descriptors. IEEE Transactions on Pattern Analysis and Machine Intelligence 26(8): 1088-1094

34. Takano D, Lenoir N, Otani J, Hall SA (2015) Localised deformation in a wide-grained sand under triaxial compression revealed by X-ray tomography and digital image correlation. Soils and Foundations 55(4): 906915

35. Thu TM, Rahardjo H, Leong EC (2006) Shear strength and pore-water pressure characteristics during constant water content triaxial tests. Journal of Geotechnical and Geoenvironmental Engineering 132(3): 411419

36. Urso MED, Lawrence CJ, Adams MJ (1999) Pendular, funicular, and capillary bridges: results for two dimensions. Journal of Colloid and Interface Science 220: 42-56

37. Vanapalli SK, Fredlund DG, Pufahl DE, Clifton AW (1996) Model for the prediction of shear strength with respect to soil suction. Canadian Geotechnical Journal 33: 379-392

38. Vanapalli SK, Nicotera MV, Sharma RS (2008) Axis Translation and Negative Water Column Techniques for Suction Control. Geotechnical and Geological Engineering 26: 645-660

39. Wang JP, Lambert P, De Kock T, Cnudde V, François B (2019) Investigation of the effect of specific interfacial area on strength of unsaturated granular materials by X-ray tomography. Acta Geotechnica published online: 15 February 2019, https://doi.org/10.1007/s11440-019-00765-2

40. Wheeler SJ, Sivakumar V (2000) Influence of compaction procedure on the mechanical behaviour of an unsaturated compacted clay. Part 2: shearing and constitutive modelling. Géotechnique 50(4): 369-376

41. Wheeler SJ, Sharma RS, Buisson, MS (2003) Coupling of hydraulic hysteresis and stress-strain behaviour in unsaturated soils. Géotechnique 53(1): 41-54 
646
42. Willson CS, Lu N, Likos WJ (2012) Quantification of grain, pore, and fluid microstructure of unsaturated sand from X-ray computed tomography images. Geotechnical Testing Journal 35(6): 911-923

43. Wulfsohn D, Adams BA, Fredlund DG (1998) Triaxial testing of unsaturated agricultural soils. Journal of Agricultural Engineering Research 69(4): 317-330

\section{Tables}

Table 1 Specimen conditions for silica sand

\begin{tabular}{ccccc}
\hline Case & CS1 & CS2 & CW1 & CW2 \\
$D_{\mathrm{r}}(\%)$ & 94.97 & 90.41 & 95.35 & 91.69 \\
Void ratio & 0.710 & 0.725 & 0.709 & 0.722 \\
Initial $S_{\mathrm{r}}(\%)$ & 63.60 & 47.60 & 60.52 & 46.20 \\
Suction $(\mathrm{kPa})$ & 1.66 & 1.70 & 1.67 & 1.69 \\
\hline
\end{tabular}

Table 2 Specimen conditions for Yodogawa sand

\begin{tabular}{ccccc}
\hline Case & CS-s10 & CS-s30 & CW-s10 & CW-s30 \\
$D_{\mathrm{c}}(\%)$ & 89.39 & 89.55 & 89.94 & 89.85 \\
Void ratio & 0.585 & 0.586 & 0.589 & 0.588 \\
Initial $S_{\mathrm{r}}(\%)$ & 49.11 & 44.50 & 47.84 & 44.22 \\
Suction $(\mathrm{kPa})$ & 10 & 30 & 10 & 30 \\
\hline
\end{tabular}


(a)

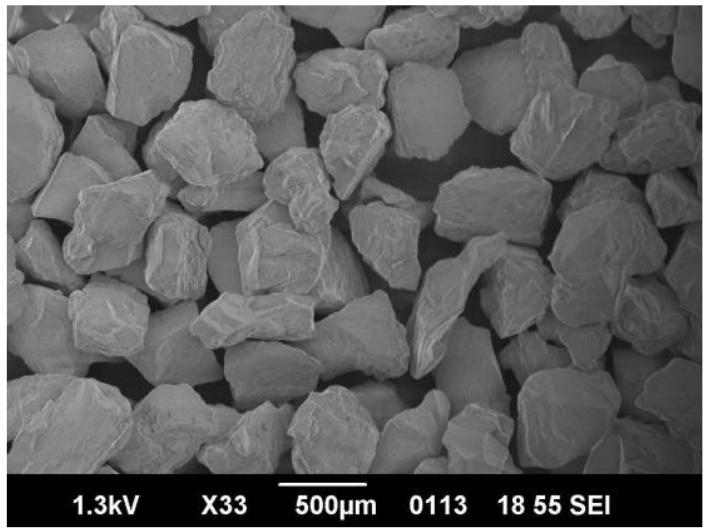

(b)

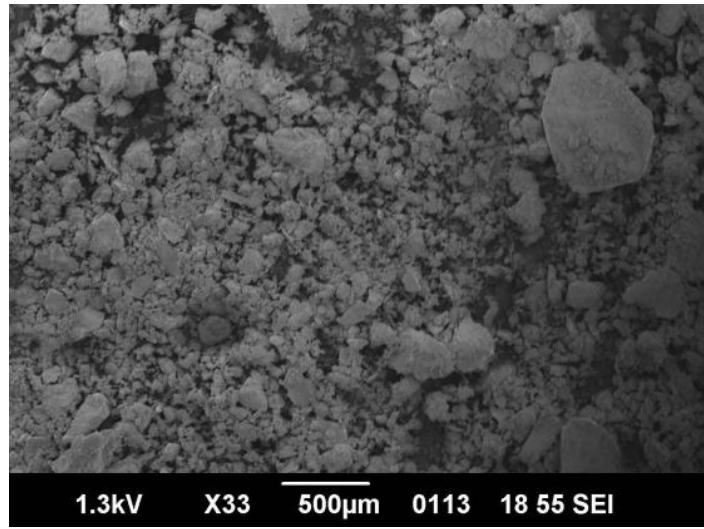

Fig. 1 SEM images: a silica sand (poorly-graded sand) and b Yodogawa sand (well-graded sand)

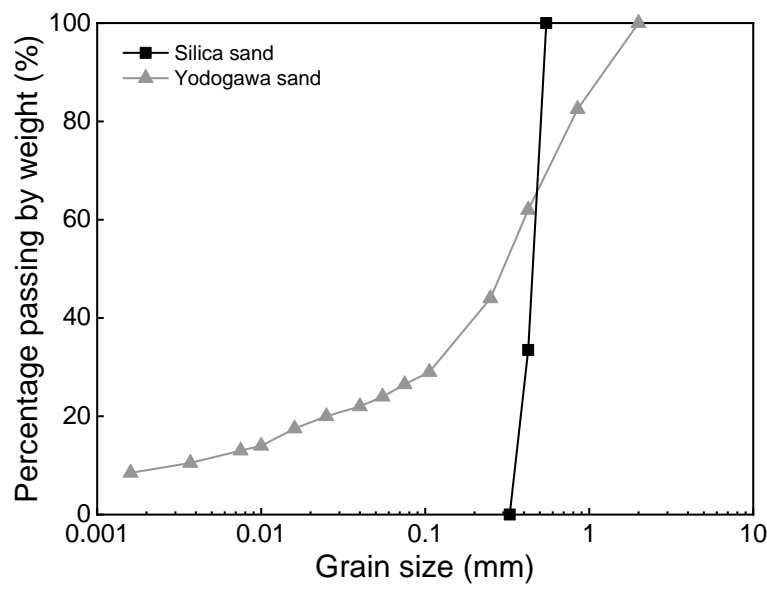

Fig. 2 Grain size distribution curves

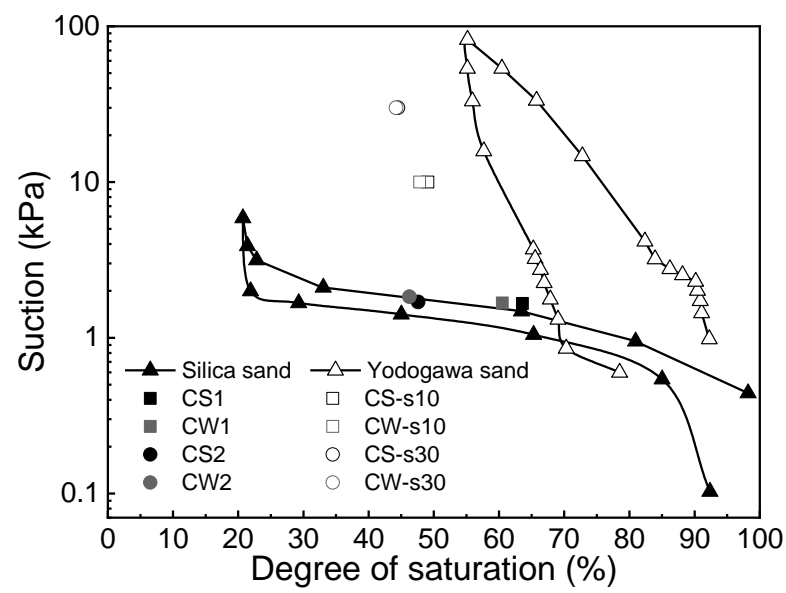

Fig. 3 Water retention curves 
(a)

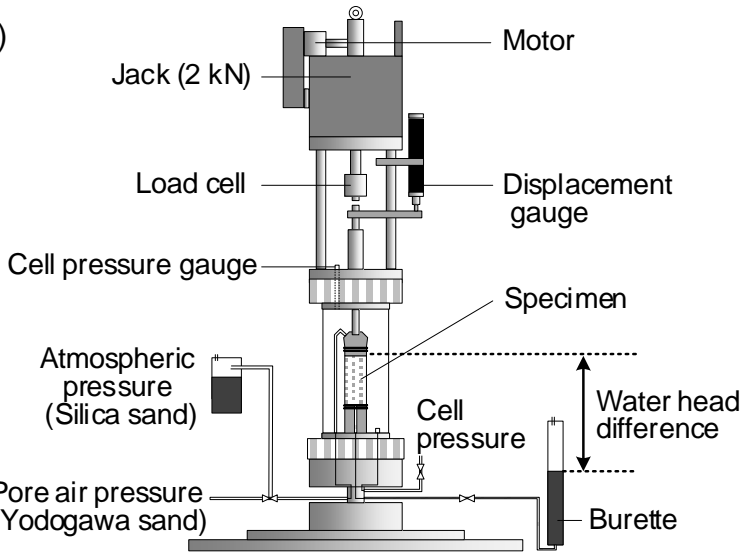

(b)

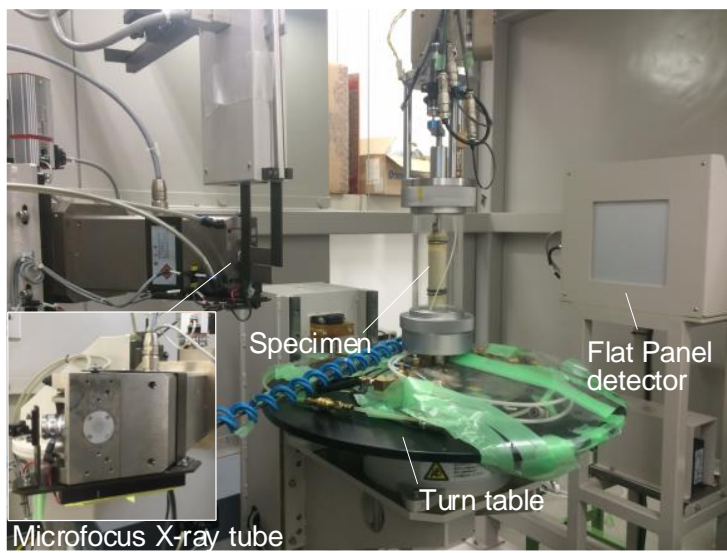

Fig. 4 a setup of triaxial compression test apparatus and $\mathbf{b}$ overview of X-ray micro tomography system

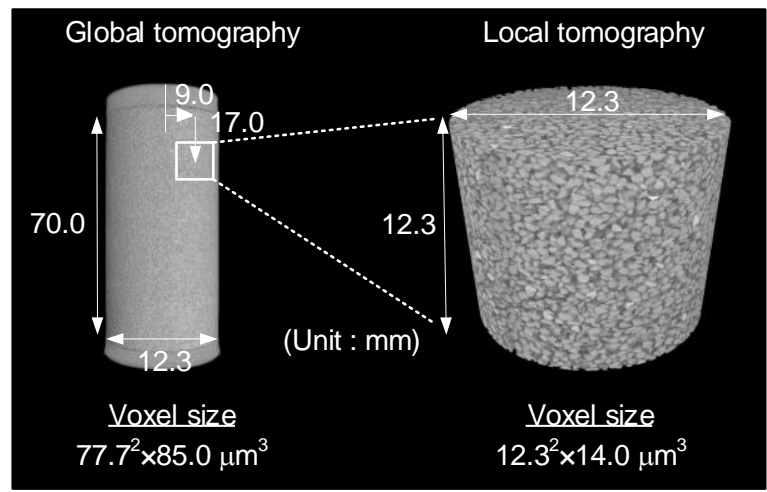

Fig. 5 Scan types with different spatial resolutions

(a)

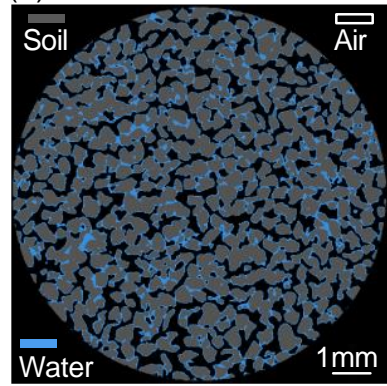

(b)

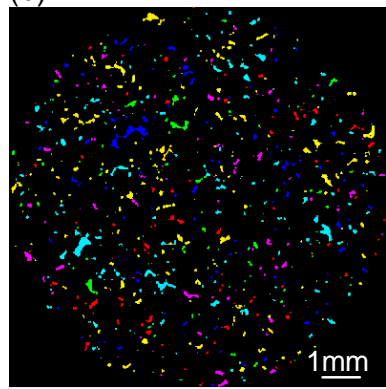

Fig. 6 Example of images: a trinarized image and $\mathbf{b}$ labeled image of pore water obtained by morphology analysis 


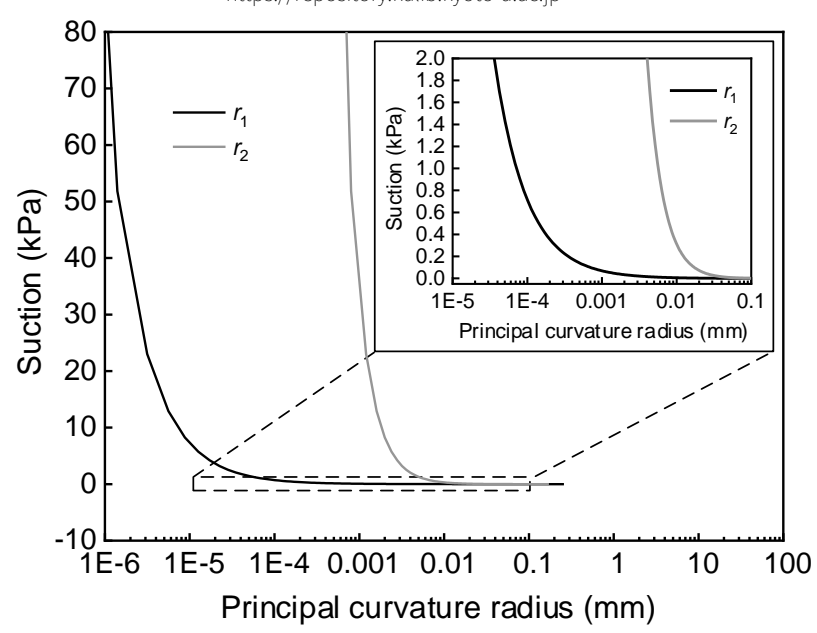

Fig. 7 Relationship between suction and principal curvature radii $r_{1}$ and $r_{2}$

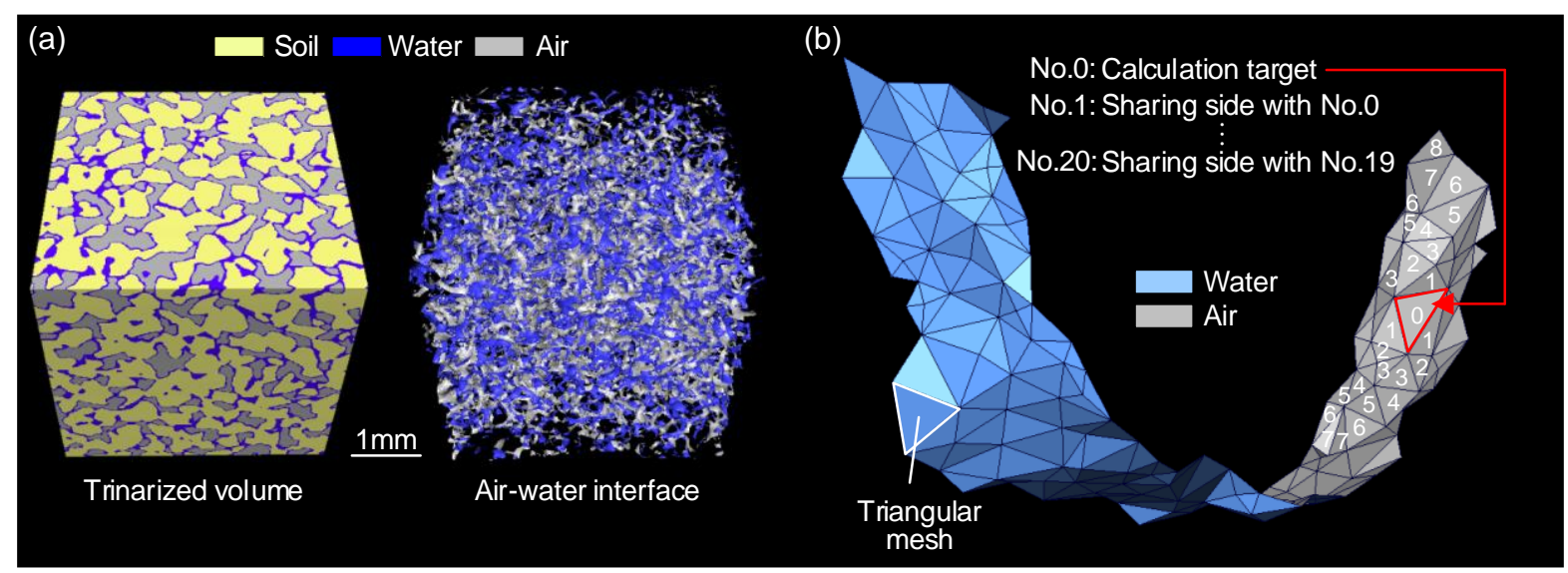

Fig. 8 a air-water interface extracted from trinarized volume and $\mathbf{b}$ triangular meshes and principle of considering neighborhood of calculation target

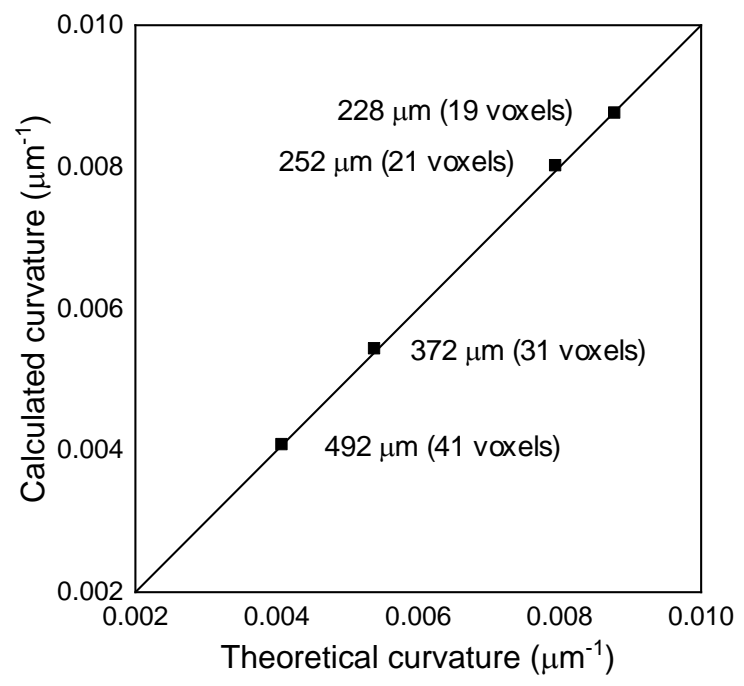

Fig. 9 Relationship between calculated curvature and theoretical curvature 

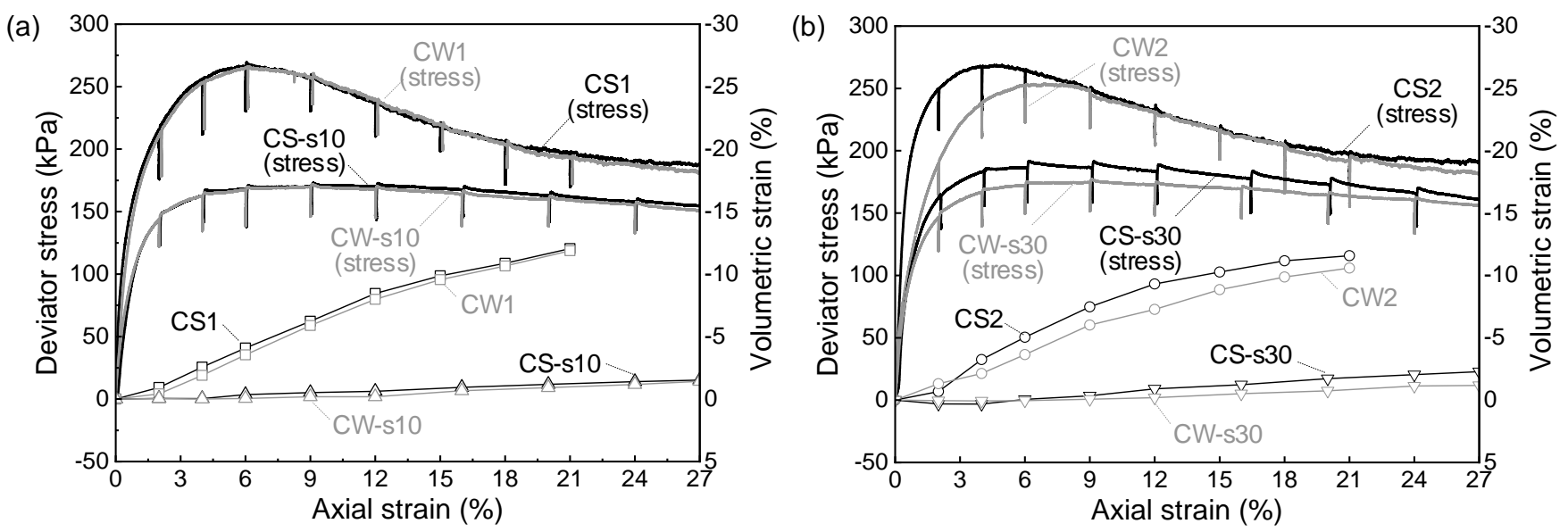

Fig. 10 Deviator stress-axial strain relationships and volumetric strain-axial strain relationships: a cases CS1, CW1, CS-s 10 and CW-s10 and $\mathbf{b}$ cases CS2, CW2, CS-s30 and CW-s30

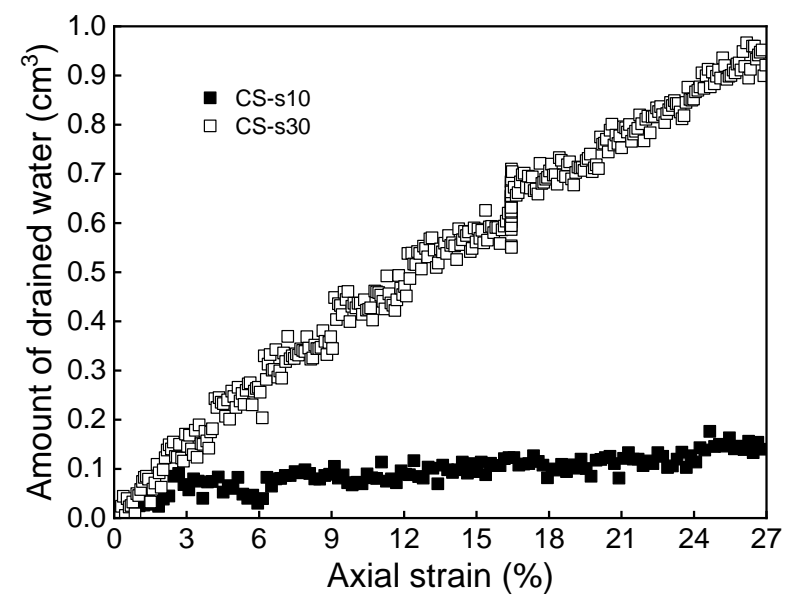

Fig. 11 Amount of drained water-axial strain relationship for cases CS-s10 and CS-s30

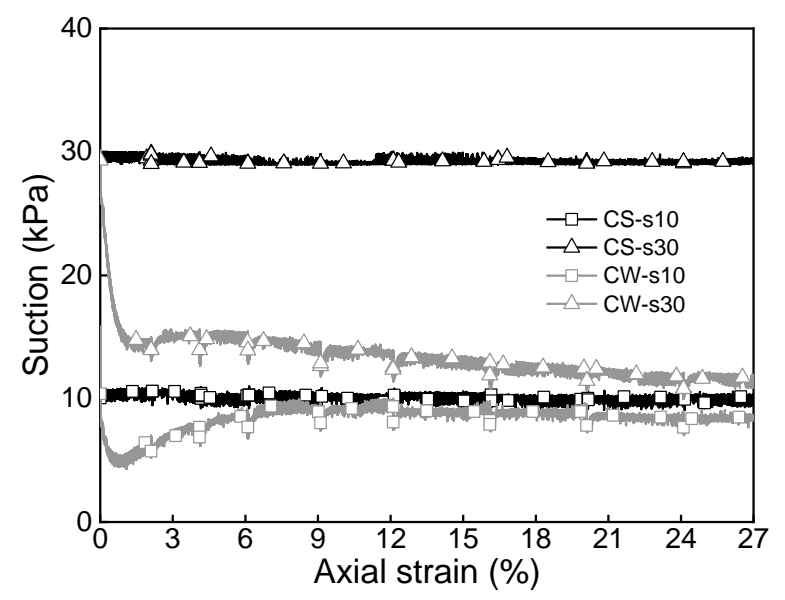

Fig. 12 Suction-axial strain relationship for Yodogawa sand 


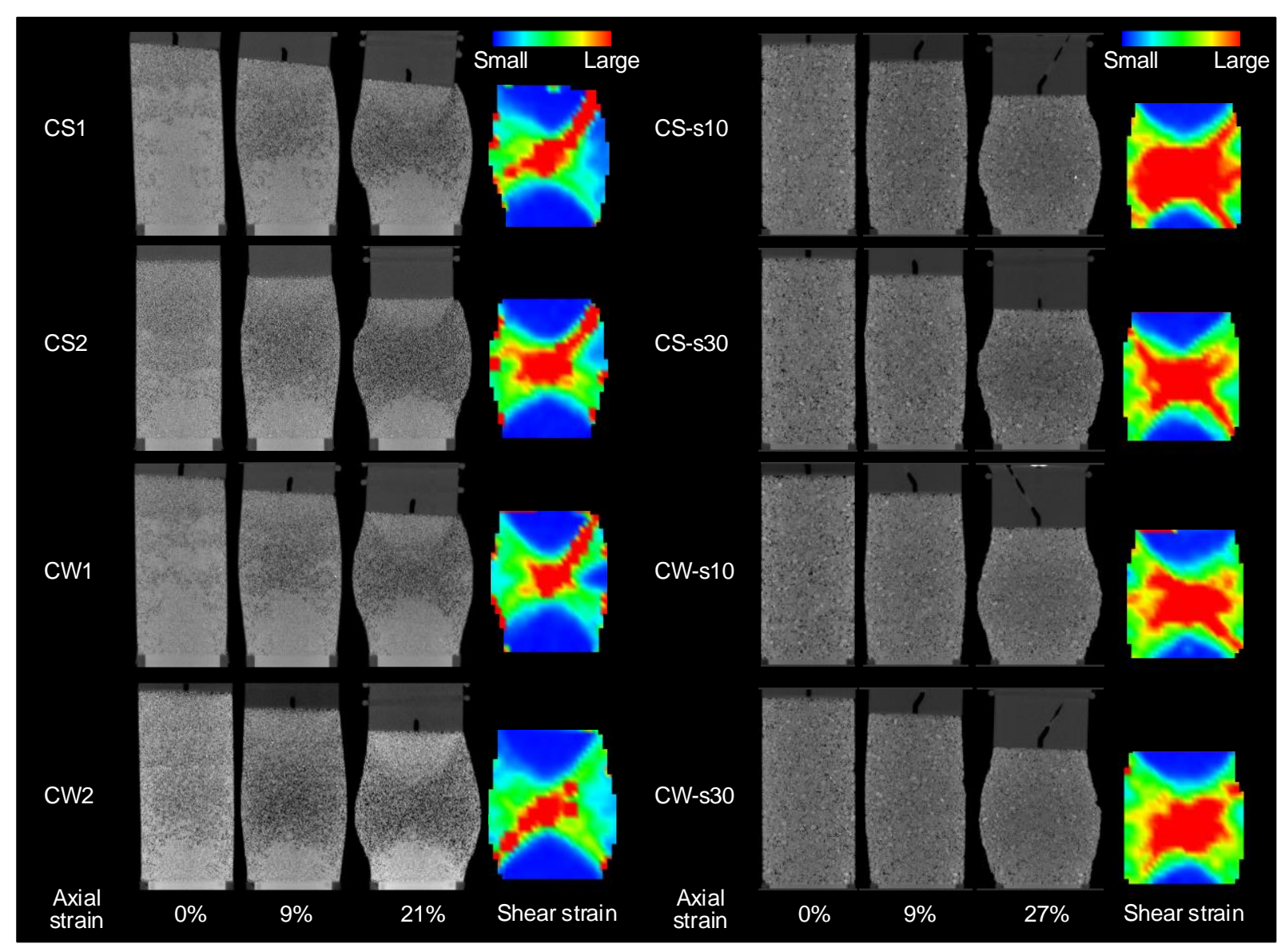

Fig. 13 Vertical slices of global tomography images and distributions of incremental shear strain
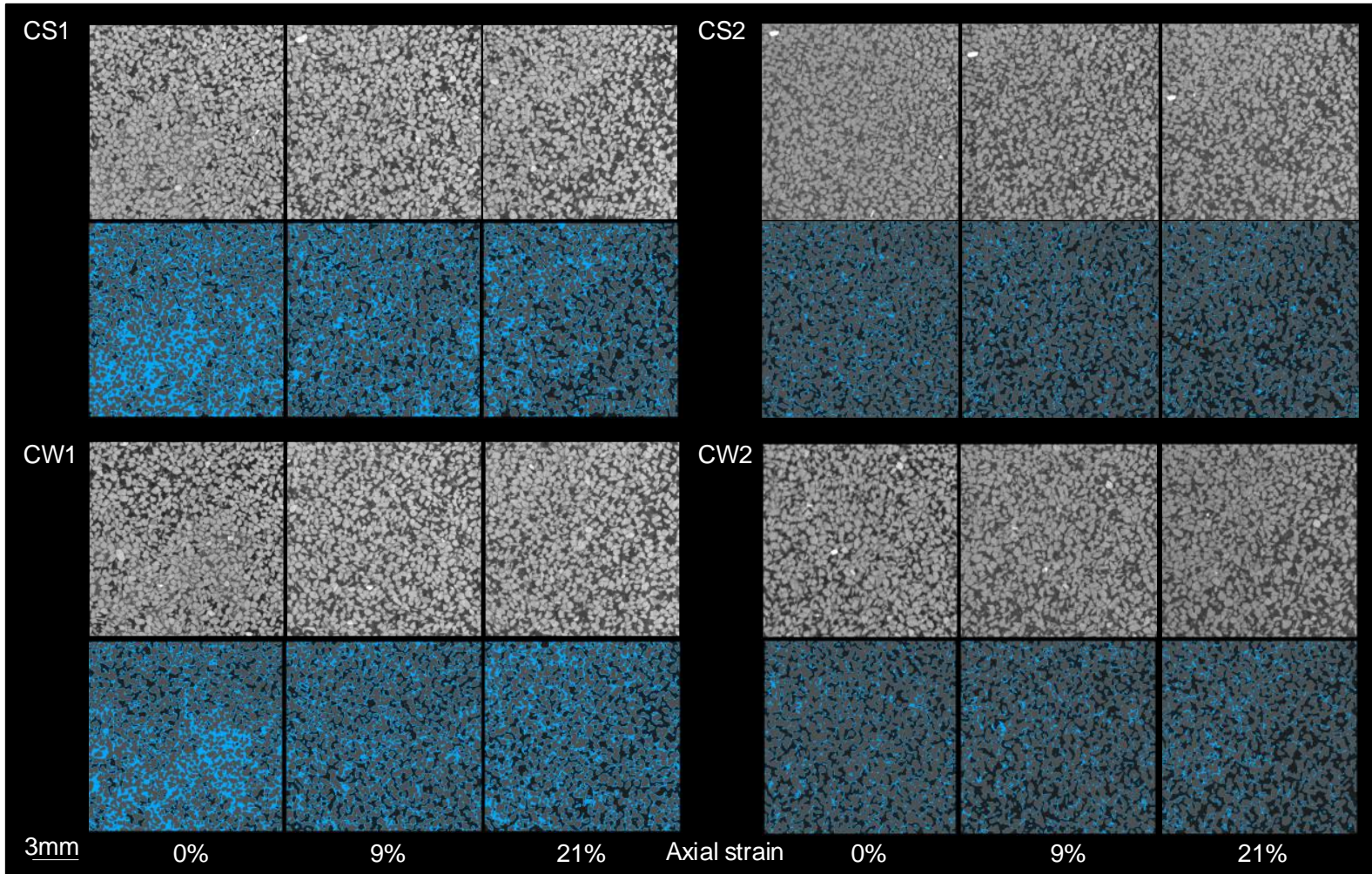

$\square$ Metal inclusion $\square$ ST imail $\square$ Water $\square$ Air

\section{Trinarized image}

Soil $\square$ Water

Fig. 14 Vertical slices of local tomography and trinarized images for silica sand 


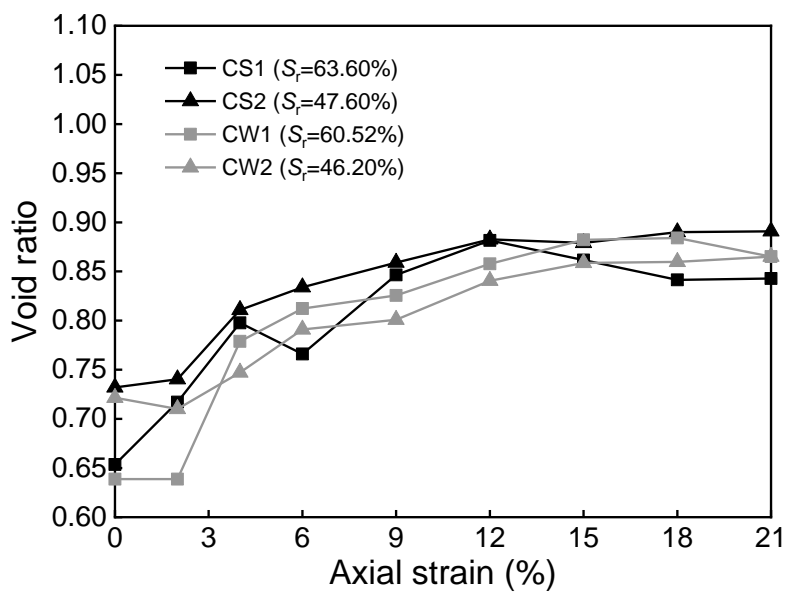

Fig. 15 Local void ratio-axial strain relationship for silica sand

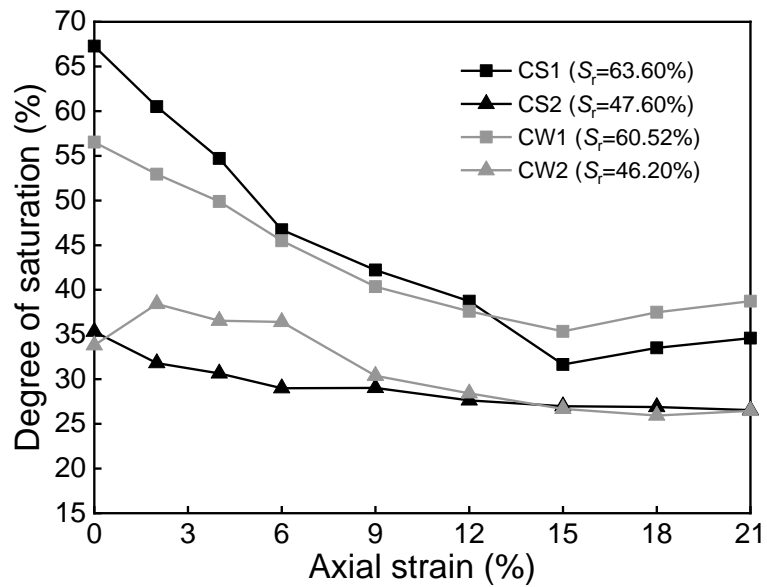

Fig. 16 Local degree of saturation-axial strain relationship for silica sand

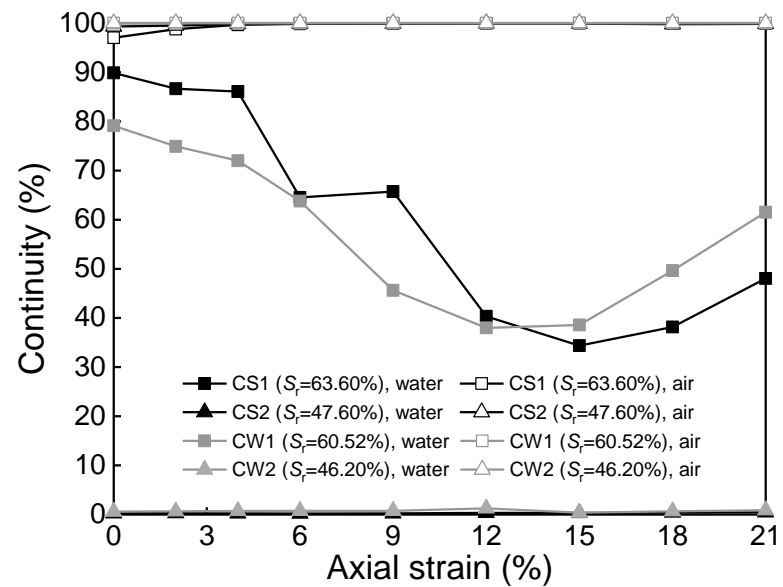

Fig. 17 Variations in continuity for pore water and pore air for silica sand 


\section{(a) $\mathrm{CS1}$}

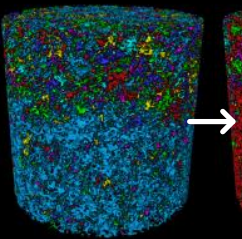

Axial strain $0 \%$

Axial strain $4 \%$

Axial strain $15 \%$

(c) CW1

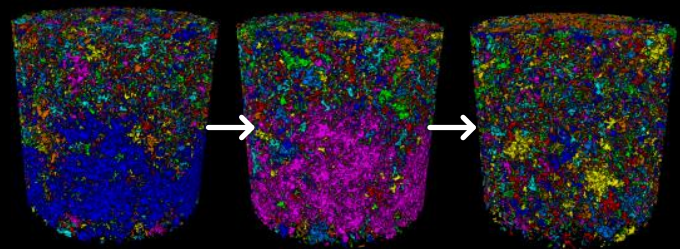

Axial strain $0 \% \quad$ Axial strain $4 \% \quad$ Axial strain $15 \%$ (b) CS2

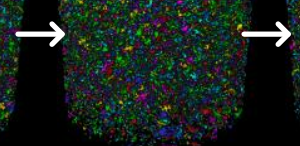

Axial strain 0\% Axial strain 4\% Axial strain 15\%

(d) CW2

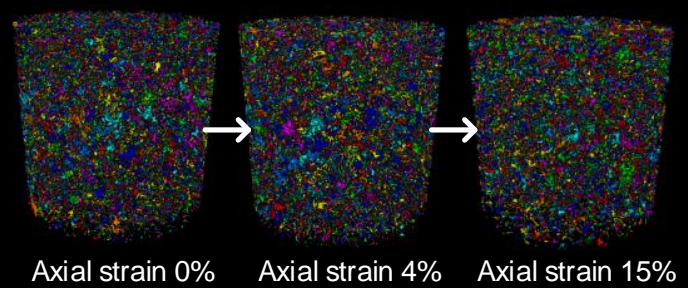

(e)

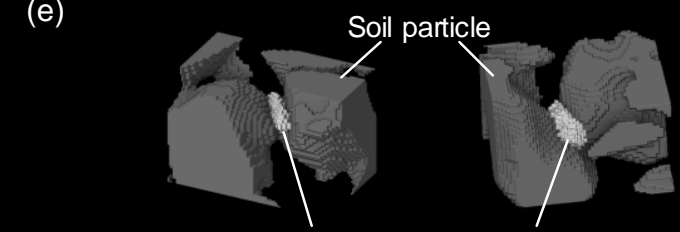

Liquid bridge

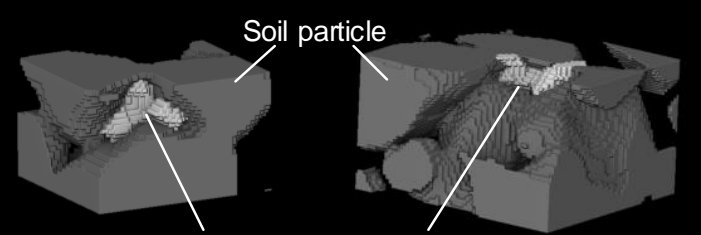

Liquid bridge

Fig. 18 Transitions of water retention states for silica sand: a case CS1, b case CS2, $\mathbf{c}$ case CW1, d case $\mathrm{CW} 2$ and $\mathbf{e}$ liquid bridges between soil particles

(a)

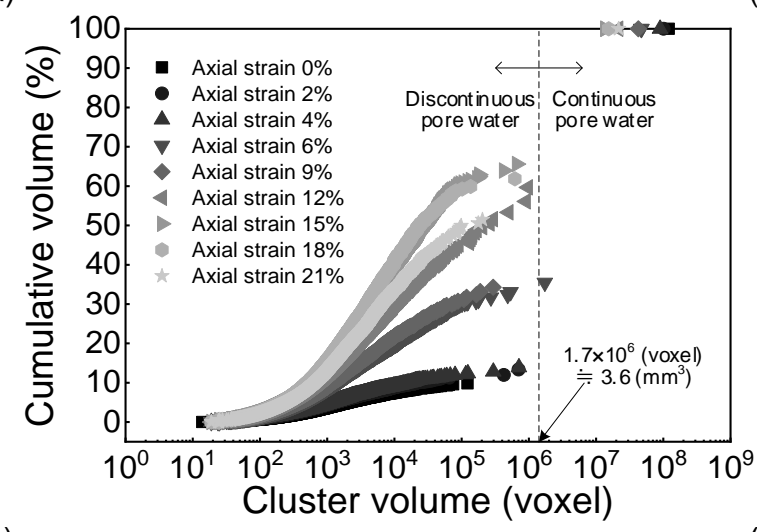

(c)

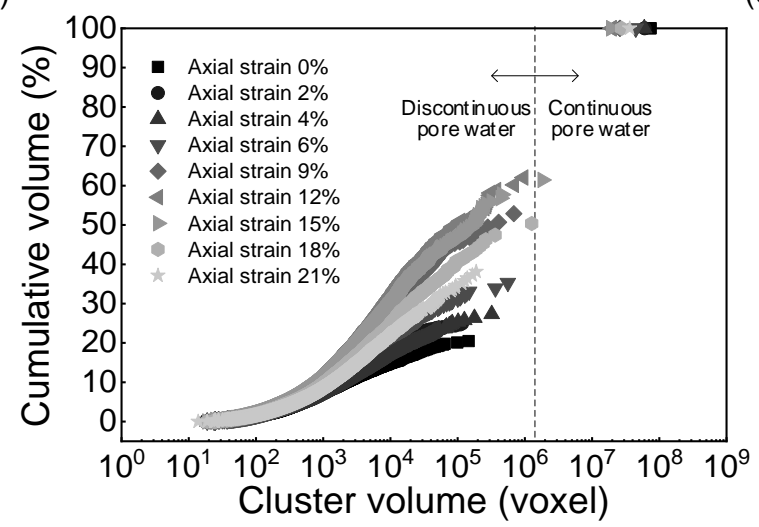

(b)

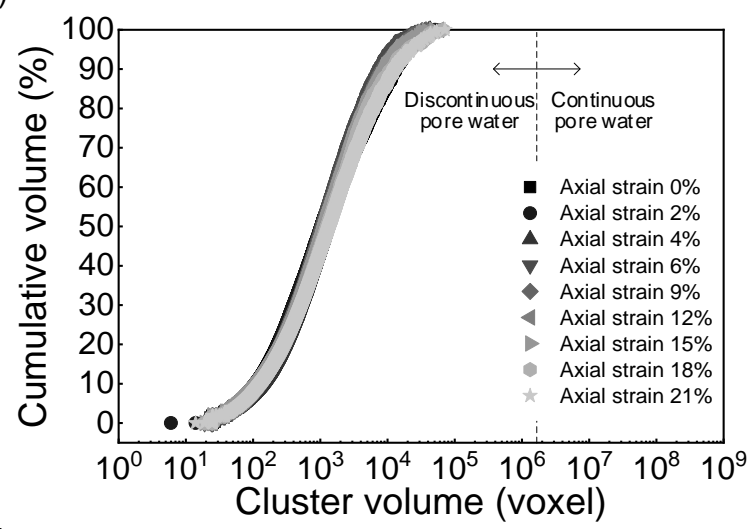

(d)

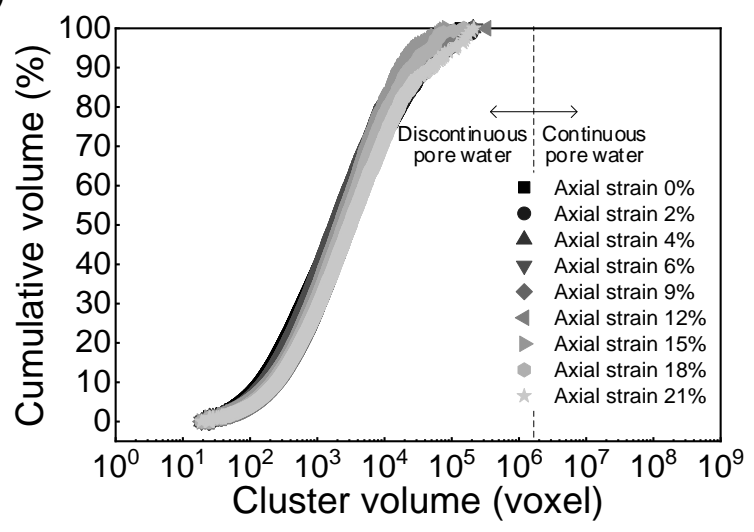

Fig. 19 Cumulative volume of pore water clusters-cluster volume relationships for silica sand: $\mathbf{a}$ case $\mathrm{CS} 1, \mathbf{b}$ case $\mathrm{CS} 2 \mathbf{c}$ case $\mathrm{CW} 1$ and $\mathbf{d}$ case CW2 

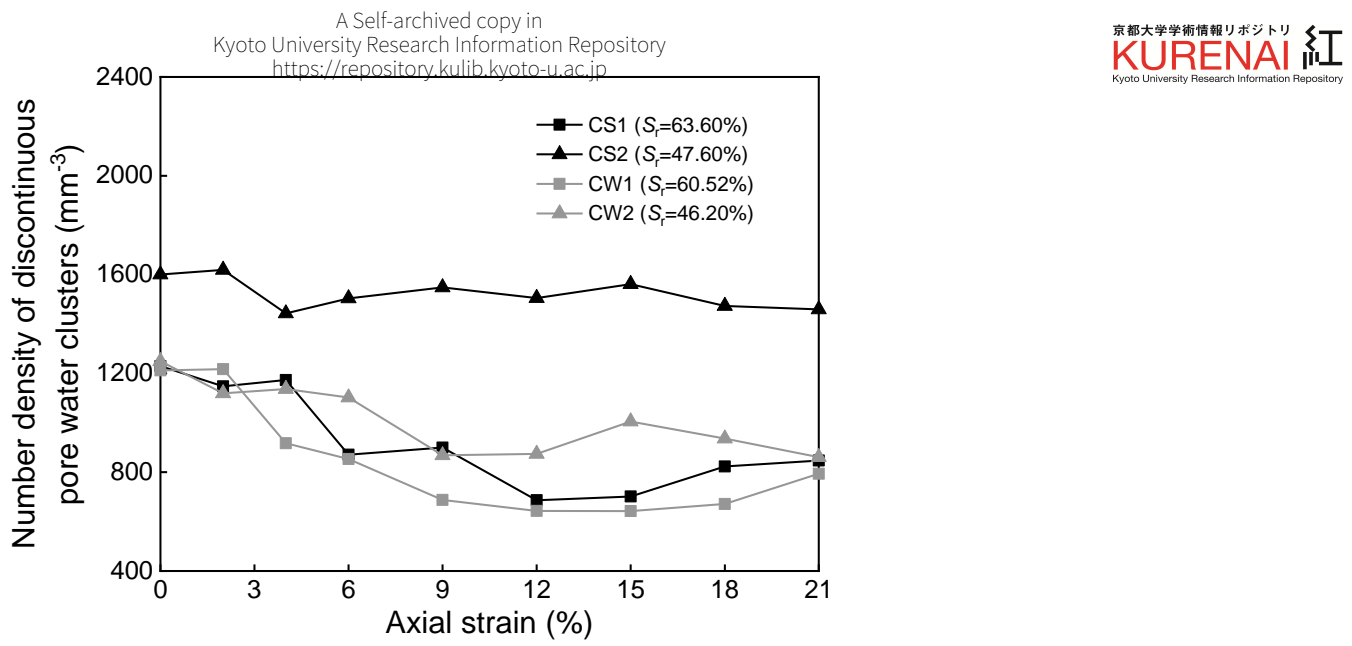

Fig. 20 Number density of discontinuous pore water clusters-axial strain relationship for silica sand

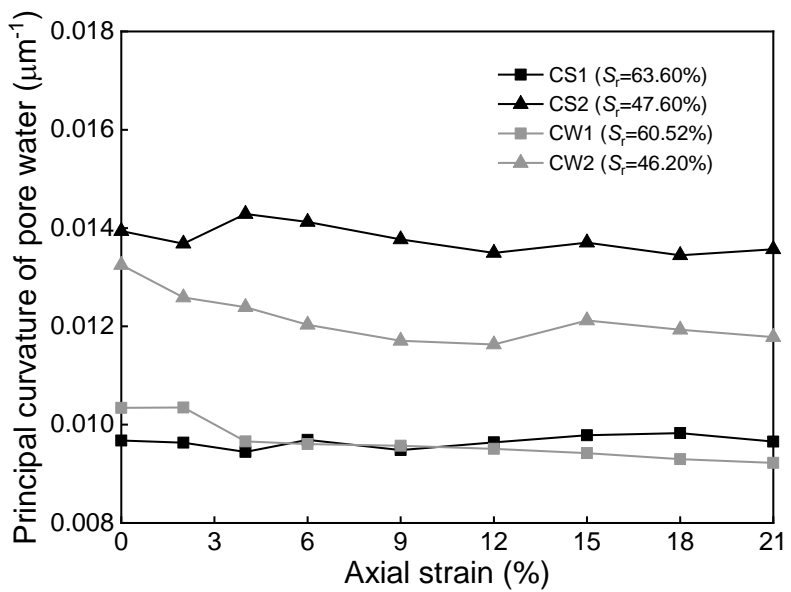

Fig. 21 Principal curvature of air-water interface-axial strain relationship for silica sand

(a)

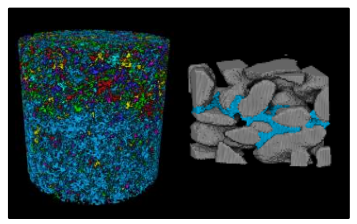

Continuous pore water (State at peak stress)

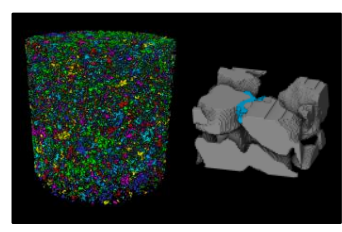

Discontinuous pore water (Critical state)

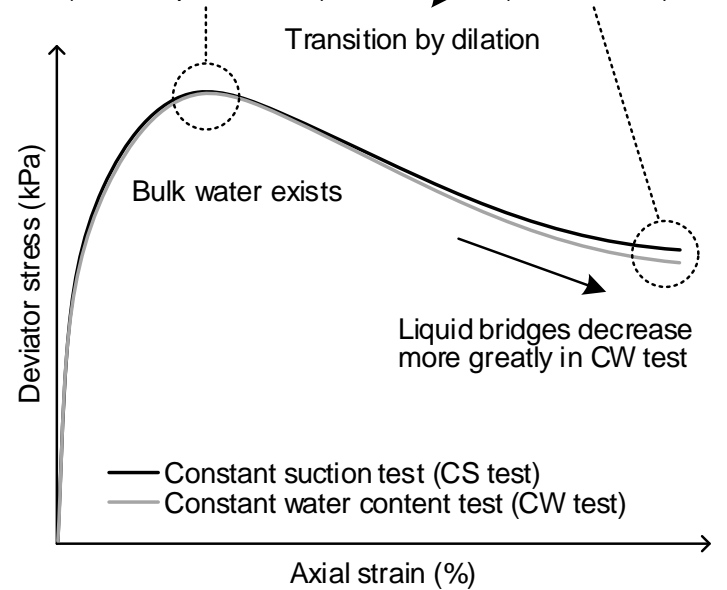

(b)

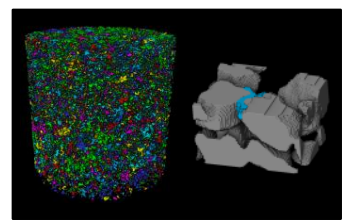

Discontinuous pore water (State at peak stress)

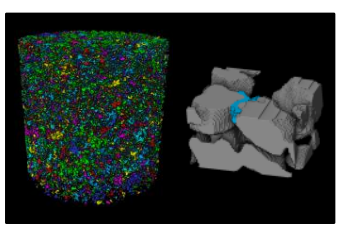

Discontinuous pore water (Critical state)

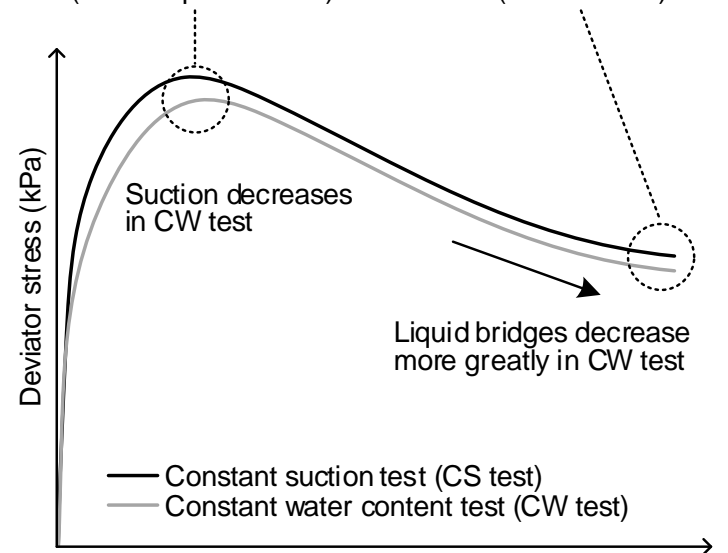

Axial strain (\%)

Fig. 22 Microscopic characteristics of partially saturated soil and their link to macroscopic responses: $\mathbf{a}$ under high initial degree of saturation and $\mathbf{b}$ under low initial degree of saturation 